\title{
Las Quinas: \\ Un nuevo sitio de la Cultura de La Aguada en San Juan
}

MARIANO GAMBIER ${ }^{1}$

\section{RESUMEN}

Se presentan los resultados del estudio del alero Las Quinas, ubicado en el valle de Iglesia (San Juan, Argentina), los cuales confirman los rasgos culturales que se habían definido para la etapa de influencia de la Cultura de La Aguada en los valles preandinos de Iglesia y Calingasta en cuanto a tipo de instalación, cultígenos, elementos de recolección, cerámica y textilería. La datación por radiocarbono señaló gran coherencia con las fechas obtenidas con anterioridad para sitios similares.

Palabras claves: San Juan - alero Las Quinas - Cultura Aguada.

\section{ABSTRACT}

The study of the Las Quinas rock shelter, in the Iglesia valley (San Juan, Argentina) confirms the existence of cultural traits that have been defined for the period of La Aguada influence in the preandean valleys of Iglesia and Calingasta, features such as settlements types, cultivated seeds, and gathering goods, ceramic and textile. Radiocarbon dating was indicated a high degreee of correspondence with dates previously obtained from similar sites.

Key words: San Juan - Las Quinas rock shelter - Aguada Culture.

Recibido: febrero 2002. Manuscrito revisado aceptado: junio 2003.

\section{Los sitios de instalación de la \\ Cultura de La Aguada en San Juan}

Varios sitios correspondientes a la manifestación local de la Cultura de La Aguada han sido localizados y estudiados en diversas zonas de la provincia de San Juan que abarcan principalmente los valles preandinos de Iglesia y Calingasta, pero también las zonas altoandinas y los valles precordilleranos de Jáchal y Zonda (Gambier 1994, 1995, 1997, 2001) (Figuras 1 y 2).

Como resultado de estos estudios se realizaron 16 fechados de radiocarbono en diferentes épocas y

1 Instituto de Investigaciones Arqueológicas y Museo FFHA, Universidad Nacional de San Juan. Ruta 40 (lateral este, entre Progreso y Calle 5), Rawson, Argentina. Email: mariano gambier@infovia.com.ar. distintos laboratorios que ubican la vigencia de la influencia Aguada en San Juan con seguridad entre los años 670 y 1060 DC. A pesar de la diversidad de sitios, los fechados muestran una coherencia indudable y simultaneidad entre los poblamientos con influencia de la Cultura de $\mathrm{La}$ Aguada de los valles de Iglesia y Calingasta (Tabla 1).

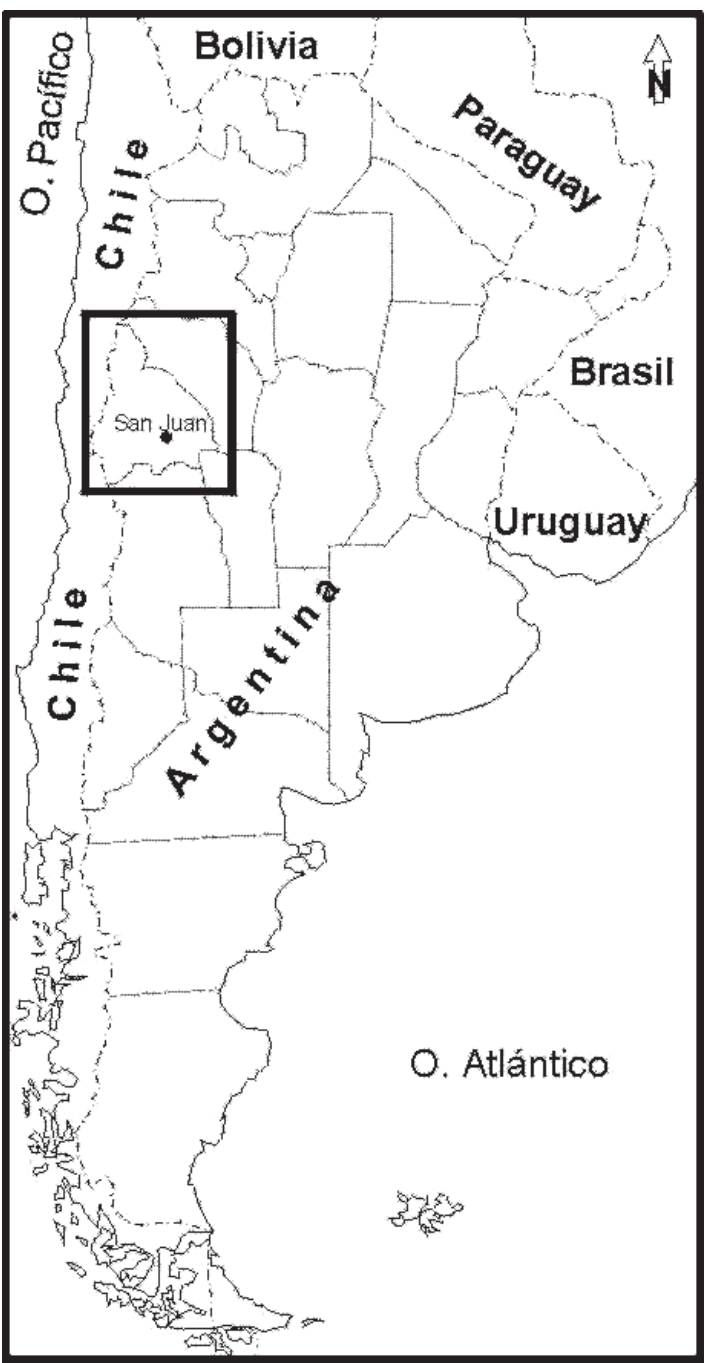

Figura 1. Mapa general que muestra la ubicación de la provincia de San Juan en Argentina. 


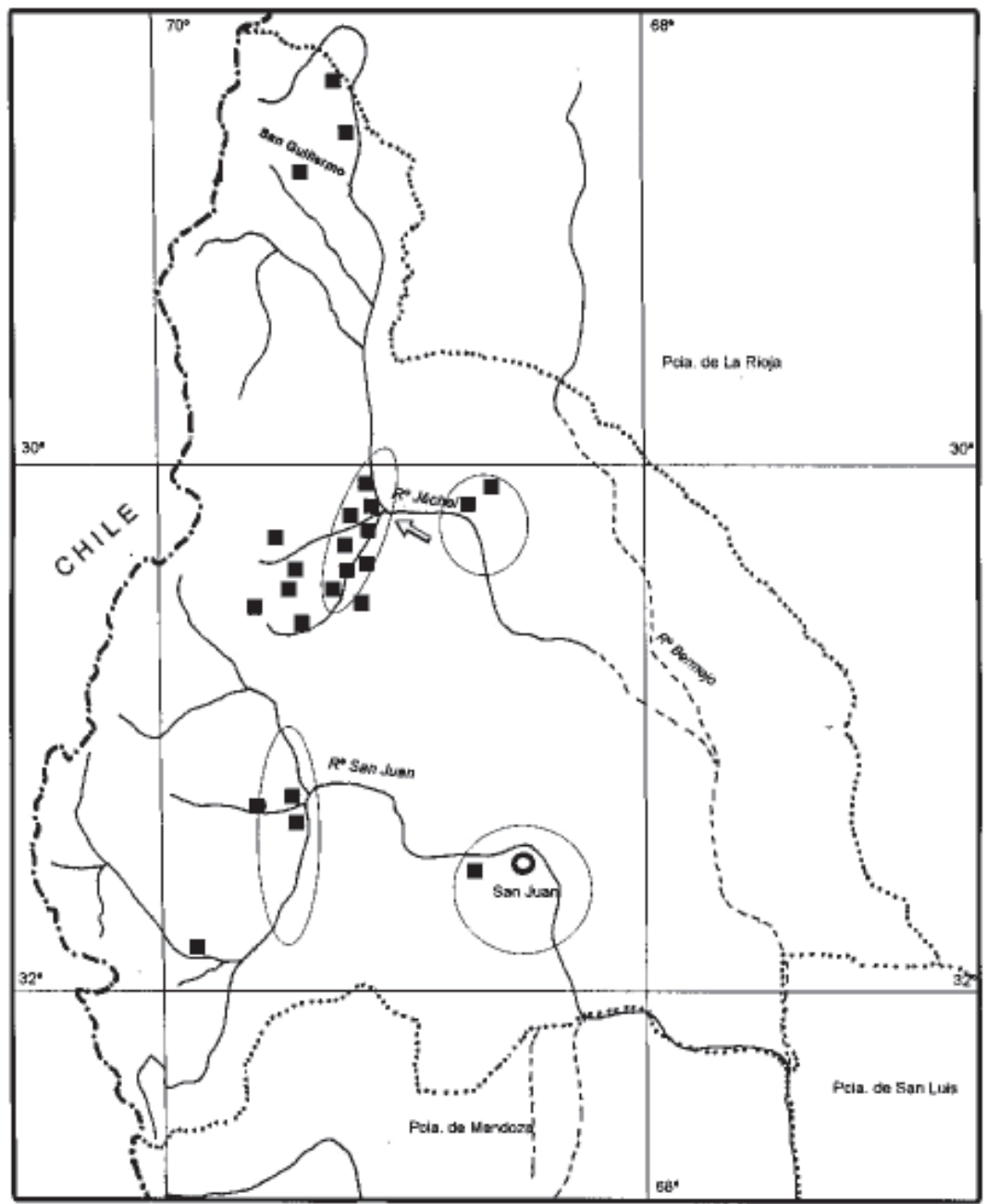

Figura 2. Sitios de la Cultura Aguada en San Juan. La flecha señala la ubicación del alero Las Quinas.

La diversidad de yacimientos estudiados permitió observar la instalación diferencial según el ambiente habitado y, por ende, el tipo de actividad económica para la explotación de recursos que los diferentes grupos de esa época realizaron.

El alto pie de monte, los valles intercordilleranos y las quebradas de acceso a la alta cordillera constituían los campos de cacería de camélidos salvajes como guanaco y vicuña, lo cual está evidenciado por las instalaciones estacionales en las zonas de sus hábitats naturales.

Es interesante ver que tanto en el norte de la zona cordillerana (región de San Guillermo) como en el sur (valles interandinos), se ubicaron también sitios con cerámica que parece muy similar al tipo
Animas definido para el Norte Chico de Chile (Castillo 1989; Castillo et al. 1997).

Los sitios ubicados en la llanura piemontana media, desfavorable para la agricultura pero rica en extensos algarrobales bajos y pasturas tardías, y principal hábitat del ñandú, contuvieron instalaciones vinculadas con la recolección de vegetales y huevos, y con el pastaje invernal o de animales en tránsito.

Los sitios ubicados en el fondo de los valles, especialmente sobre tierra de barreales con altas temperaturas, fueron los más densamente poblados. En ellos, la actividad preponderante fue la agricultura de regadío a partir del aprovechamiento de manantiales y pequeños arroyos. 


\begin{tabular}{|c|c|c|}
\hline FECHA & VALLE DE IGLESIA & VALLE DE CALINGASTA \\
\hline $\begin{array}{l}1060 \\
880 \text { (cal DC) } \\
860 \\
855 \text { (cal DC) } \\
840 \\
790 \\
770 \text { (cal DC) } \\
750 \\
745 \\
740 \\
730 \\
710 \\
670 \\
610\end{array}$ & 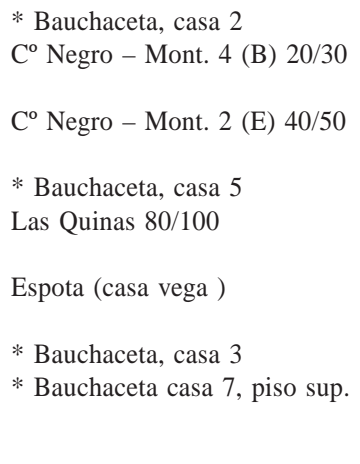 & $\begin{array}{l}\mathrm{C}^{\text {o }} \text { Calvario II - sondeo prof. } \\
\text { Alto Verde - Gr. } 11 \text { (madera de construcción) } \\
\text { Alto Verde - Gr. } 4 \text { - C }{ }^{\text {o }} \text { Calvario III, sondeo 3, piso sup. } \\
C^{\circ} \text { Calvario IV - } 25 / 45 \\
C^{\circ} \text { Calvario - Lomo Sur } 80 / 90 \\
C^{o} \text { Calvario III - sondeo } 8 \text { - piso } \\
\text { Alto Verde - Gr. } 11 \text { (carbón) }\end{array}$ \\
\hline
\end{tabular}

Tabla 1. Fechas obtenidas por radiocarbono. ${ }^{2}$

Las evidencias vegetales indican que se cultivó maíz (Zea mayz), zapallo (Cucurbita maxima y C. pepo), mate (Lagenaria sp.), poroto (Phaseolus vulgaris), quínoa (Chenopodium quinoa) y, en menor medida, maní (Arachis sp.) y algo de algodón (Gossypium sp.).

Juntamente con la agricultura, también se explotó la llama como animal doméstico y como medio de transporte. Los pequeños corrales adosados a las viviendas contienen restos de estiércol apisonado donde se mezclan desperdicios domésticos, que evidentemente fueron utilizados como forraje; este estiércol, a su vez, se utilizó como abono y combustible.

\section{El sitio Las Quinas}

Si bien los trabajos de campo sistemáticos que siguieron el desarrollo y expansión de esta etapa de la prehistoria local finalizaron en 1993, con motivo de la amplia prospección realizada a partir de 1995 sobre los yacimientos de los momentos tardíos, se pudo localizar otro importante sitio correspondiente a la Cultura de La Aguada en San Juan. El mismo, conocido como Las Quinas, consiste en un alero que fue excavado en julio de 1996.

2 Todos los fechados fueron realizados por el autor entre los años 1971 y 1998. Aquellos correspondientes a los sitios de Bauchaceta (señalados con asterisco) que datan de 1973, fueron publicados con anterioridad (Gambier 1975), mientras que los restantes fueron comunicados en el XIII Congreso Nacional de Arqueología Argentina realizado en Córdoba en 1999 (Gambier 2001).
Se ubica a $\operatorname{los} 30^{\circ} 11^{\prime}$ Lat. S y $69^{\circ} 8^{\prime}$ Long. O, a un par de kilómetros de la ruta que une la localidad de Rodeo con la de Cerro Negro, en la parte más baja del valle de Iglesia, a los $1.720 \mathrm{~m} . \mathrm{snm}$ (Figura 3). Está en la parte más alta de una pequeña quebrada seca que se abre hacia el suroeste y desemboca sobre el cauce del arroyo Las Quinas, cuyas nacientes constituyen el aporte de agua del sitio.

A $15 \mathrm{~m}$ de altura sobre el margen derecho de la pequeña quebrada, se encuentran los restos de una gruta derrumbada que, hacia el suroeste se transforma en un estrecho alero de unos $30 \mathrm{~m}$ de extensión. De sus oquedades, algunos lugareños habían extraído con dificultad restos arqueológicos de una etapa tardía. Esto motivó su interés de obtener otros elementos, por lo que dinamitaron el extremo del alero, lo que produjo un pozo de unos $2 \mathrm{~m}$ de diámetro y $1.5 \mathrm{~m}$ de profundidad y ocasionó un peligroso resquebrajamiento y debilitamiento de las paredes del alero. Por los restos que estas personas habían recogido del pozo producido por la dinamita (entre ellas un palo trabajado de $1 \mathrm{~m}$ de longitud y $7 \mathrm{~cm}$ de diámetro, aproximadamente) y los que se recolectaron en el momento de la prospección, pudo observarse que en el alero había existido una instalación de la época de la influencia Aguada.

Se procedió entonces a realizar una excavación de $1.50 \mathrm{~m}$ de ancho a lo largo de la pared del alero desde el pozo hacia la gruta. El trabajo fue peligroso por lo estrecho del sitio, lo empinado del talud del mismo y la amenaza permanente de caída de bloques rocosos del alero debilitado por 


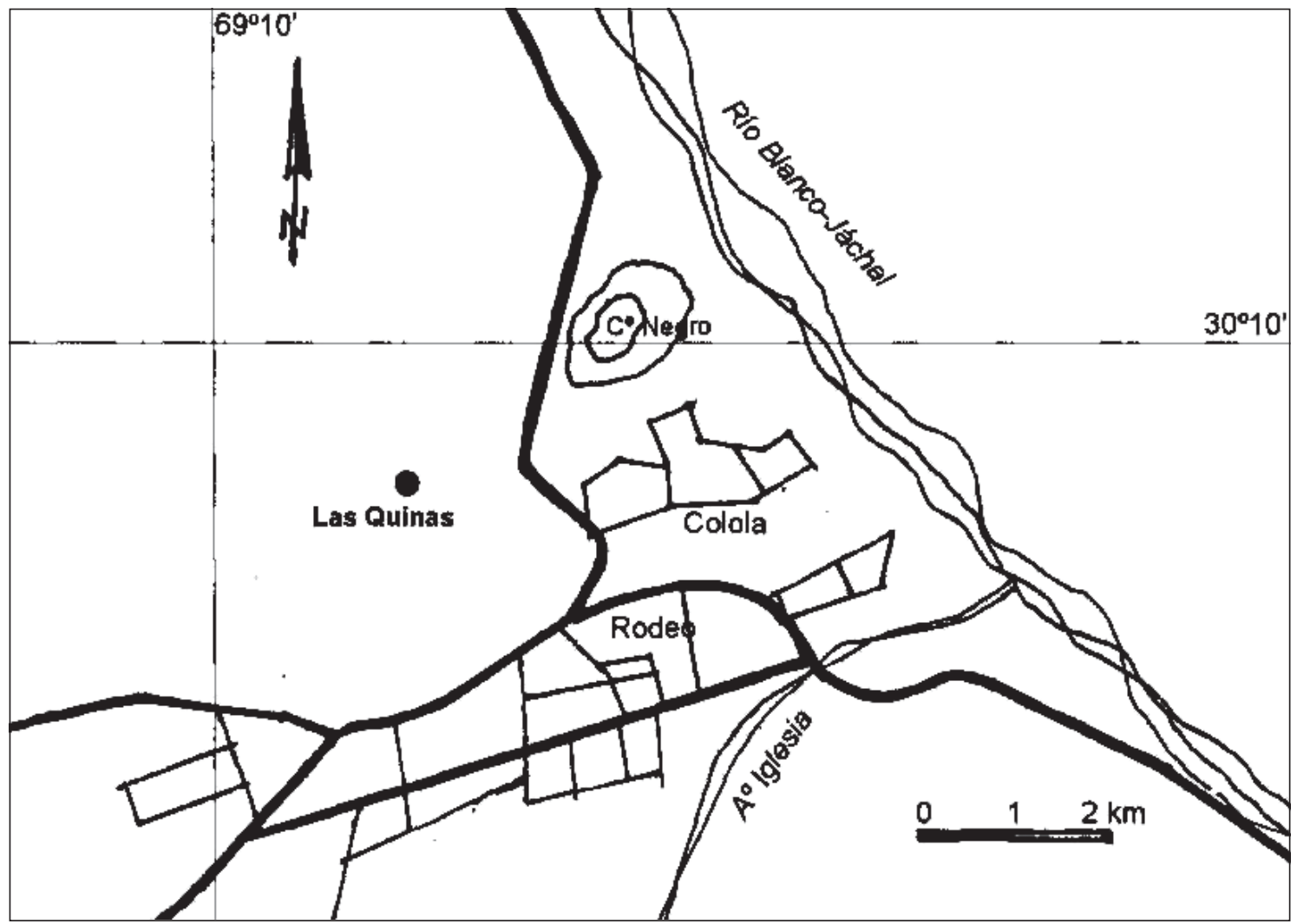

Figura 3. Ubicación del alero Las Quinas en el valle de Iglesia.

la explosión. Se observó que, sobre el piso natural del alero, se hallaba una acumulación de 40 a $60 \mathrm{~cm}$ de sedimentos arqueológicos de la etapa en estudio, sobre la cual se apoyaba un grueso estrato de derrumbes que servía como sello natural. Los sedimentos arqueológicos brindaron gran cantidad y variedad de elementos que sirvieron para ratificar gran parte de las observaciones realizadas anteriormente en otros sitios.

\section{Los materiales arqueológicos}

De la excavación se rescató un interesante muestrario de diversos materiales, incluyendo restos perecederos.

Se obtuvieron fragmentos de cerámica Aguada policromos con interior negro bruñido y gris-negro pulido (Figura 4), entre otras varias evidencias de cerámica común no demasiado burda. Entre los elementos perecederos conservados se destacan restos de vegetales cultivados: maíz (granos, chalas y corontas), zapallo, mate y poroto. También sobresalen una estatuilla antropomorfa de barro crudo con ojos tipo "grano de café" (Figura 5), una espátula de hueso y cuentas de conchillas marinas; estiércol humano y de ñandú y llama; huesos diversos y cáscara de huevo de ñandú; espiches ${ }^{3}$ de madera; maderas y cañas diversas, especialmente de carrizo (Phragmites australis), e incluso un fragmento de coligüe (Chusquea sp.). También se halló gran cantidad de restos que incluyen tientos de cuero, retorcidos vegetales de hojas de cortadera (Cortaderia sp.) para el atado de haces de cañas de las paredes de las viviendas, cestería en espiral, hilos de lana y fibra vegetal y fragmentos de tejido realizados en técnica de tejido llano con hilos de lana y de fibra vegetal. Estos hallazgos ratifican los elementos definidos por Michieli (1997, 2001) como integrantes del conjunto textil típico de Aguada para la zona. Entre los elementos de recolección se halló algarrobo (Prosopis sp.), cha-

\footnotetext{
"Estaquilla que sirve para cerrar un agujero, como las que se colocan en las cubas para que no salga el líquido o en los botes para que no se aneguen" (Real Academia Española).
} 


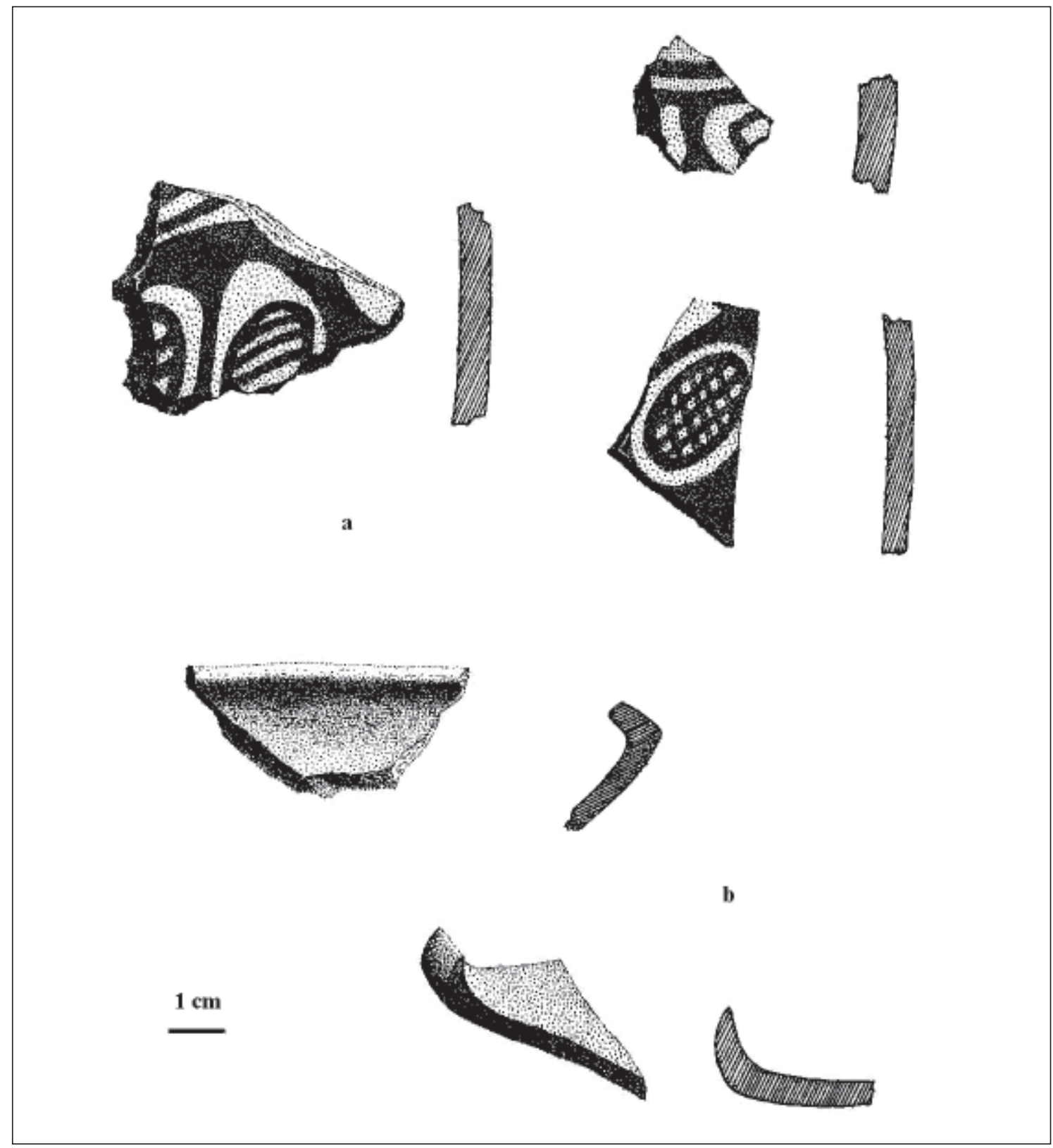

Figura 4. Cerámica Aguada del alero Las Quinas: a) policromo con interior negro bruñido; b) cerámica gris-negra pulida (dibujos de Américo N. Díaz).

ñar (Geoffroea decorticans), y gran cantidad de pequeños carozos similares a los que ya habían sido recolectados en otros sitios como Cerro $\mathrm{Ne}$ gro. No existe ninguna especie en la zona de la cual procedan carozos similares. Por comparación se ha podido establecer que pueden tratarse de carozos de la drupa del mistol (Zizyphus mistol), árbol propio de la flora chaqueña. Hasta ahora, la comparación morfológica con micros- copía común ha mostrado una gran similitud entre estas semillas y semillas actuales de mistol, proveniente de la provincia de Santiago del Estero. Si bien la comparación morfológica externa es más difícil, la comparación morfológica interna ha dado un $90 \%$ de posibilidad de que pertenezcan al mismo género, del cual sólo existe una especie en la Argentina. En estos momentos se está procediendo a la extracción de ácidos 


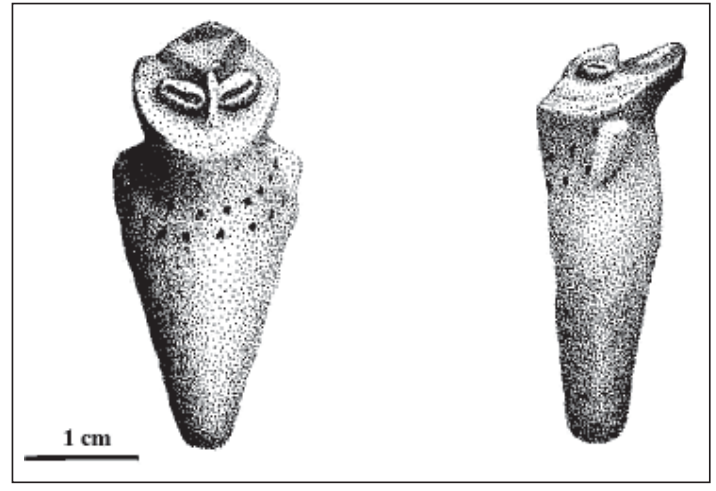

Figura 5. Estatuilla antropomorfa de barro crudo (dibujo de Américo N. Díaz).

nucleicos con lo que se podría asegurar un $99 \%$ de certeza. ${ }^{4}$

Se realizó un fechado de radiocarbono ${ }^{5}$ sobre carbonilla de un fogón ubicado en la base de los sedimentos que dio $1270 \pm 50$ AP con edad calibrada (con dos sigmas de probabilidad) entre 665 a 885 DC (intercepción de la curva de calibración en 770 DC), que resulta coincidente con los otros fechados de la región (Tabla 1).

\section{Conclusiones}

El emplazamiento, datación y elementos culturales del sitio Las Quinas, ratificaron los rasgos y características de la influencia Aguada sobre los grupos locales de San Juan, tal como ha sido publicado anteriormente (Gambier 1997, 2000, 2001).

El tipo de instalación en el sitio reproduce la ubicación de viviendas adosadas a un corte de la falda de loma o cerro, de planta rectangular alargada y con paredes externas e internas de quincha realizada con haces de cañas de carrizo, atados con retorcidos vegetales y cubiertos con barro, que son las típicas de las zonas más bajas de los valles.

La abundante presencia de carozos similares a los del mistol abre una nueva posibilidad de considerar el traslado de elementos alimenticios y/u otros desde zonas que se consideran centrales en el desarrollo de Aguada, como es la región con flora chaqueña.

\section{REFERENCIAS CITADAS}

CASTILlO, G., 1989. Agricultores y pescadores del Norte Chico: El Complejo Las Animas (800-1200 DC). En: Culturas de Chile. Prehistoria, desde sus orígenes hasta los albores de la conquista, J. Hidalgo, V. Schiappacasse, H. Niemeyer, C. Aldunate e I. Solimano (Eds.), pp. 265276. Editorial Andrés Bello, Santiago.

CASTILLO, G., H. NIEMEYER y M. CERVELLINO, 1997. Indicadores, alcances y perspectivas de las influencias Aguada en el valle de Copiapó, Chile. Shincal 6: 193212

GAMBIER, M., 1975. Las habitaciones semisubterráneas de Bauchaceta, Iglesia, San Juan. Publicaciones I. IIAM UNSJ, San Juan.

1994. La Cultura de La Aguada en San Juan. Revista Ansilta 7: 14-19.

4 Los estudios botánicos están siendo realizados por la Dra. Rosa María Gambier en el Departamento de Biología del Centro de Enseñanza de Biotecnología del Suffolk Community College (New York).

5 Beta-118067: Las Quinas 80/100.
_ 1995. La Cultura de La Aguada en San Juan. II. Revista Ansilta 8: 14-20.

_ 1997. La expansión de la Cultura de La Aguada en San Juan. Shincal 6: 173-192.

-2000. Prehistoria de San Juan (Segunda edición). Ansilta, San Juan.

2001. Identificación de la cultura de La Aguada en San Juan: Las manifestaciones agropastoriles anteriores al 1000 DC. Actas del XIII Congreso Nacional de Arqueología Argentina, Tomo I, pp. 95-100. Córdoba (1999).

MICHIELI, C. T., 1997. Textilería Aguada en San Juan (comunicación preliminar). Shincal 6: 233-240.

2001. Textilería Aguada en el valle de Iglesia, Provincia de San Juan. Publicaciones 24: 23-42. 